\title{
Stereodivergent Approach to the Asymmetric Synthesis of Bacillariolides. A Formal Synthesis of ent-Bacillariolide II
}

Subrata Ghosh* ${ }^{\dagger}$, Saikat Sinha ${ }^{\dagger}$ and Michael G. B. Drew ${ }^{\ddagger}$

'Department of Organic Chemistry, Indian Association for the Cultivation of Science, Jadavpur, Kolkata 700 032, India and Department of Chemistry, The University, Whitenknights, Reading RG6 6AD, UK

\section{Table of contents}

\section{Supporting Information}

1. Experimental Procedure and spectral data ------o------o----- S2

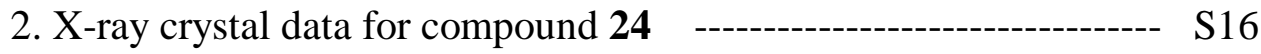

3. ${ }^{1} \mathrm{H}$ and ${ }^{13} \mathrm{C}$ NMR of compound 1 -

4. ${ }^{1} \mathrm{H}$ and ${ }^{13} \mathrm{C}$ NMR of compound 3------ S20

5. ${ }^{1} \mathrm{H}$ and ${ }^{13} \mathrm{C}$ NMR of compound 18

6. ${ }^{1} \mathrm{H}$ and ${ }^{13} \mathrm{C}$ NMR of compound 23 -

7. ${ }^{1} \mathrm{H}$ and ${ }^{13} \mathrm{C}$ NMR of compound 19 --------- S23

8. ${ }^{1} \mathrm{H}$ and ${ }^{13} \mathrm{C}$ NMR of compound 25 --o-- S24

9. ${ }^{1} \mathrm{H}$ and ${ }^{13} \mathrm{C}$ NMR of compound 20 -

10. ${ }^{1} \mathrm{H}$ and ${ }^{13} \mathrm{C}$ NMR of compound 26 ----- S26

\section{SPECTRA \\ ${ }^{1} \mathrm{H}$ and ${ }^{13} \mathrm{C}$ NMR}



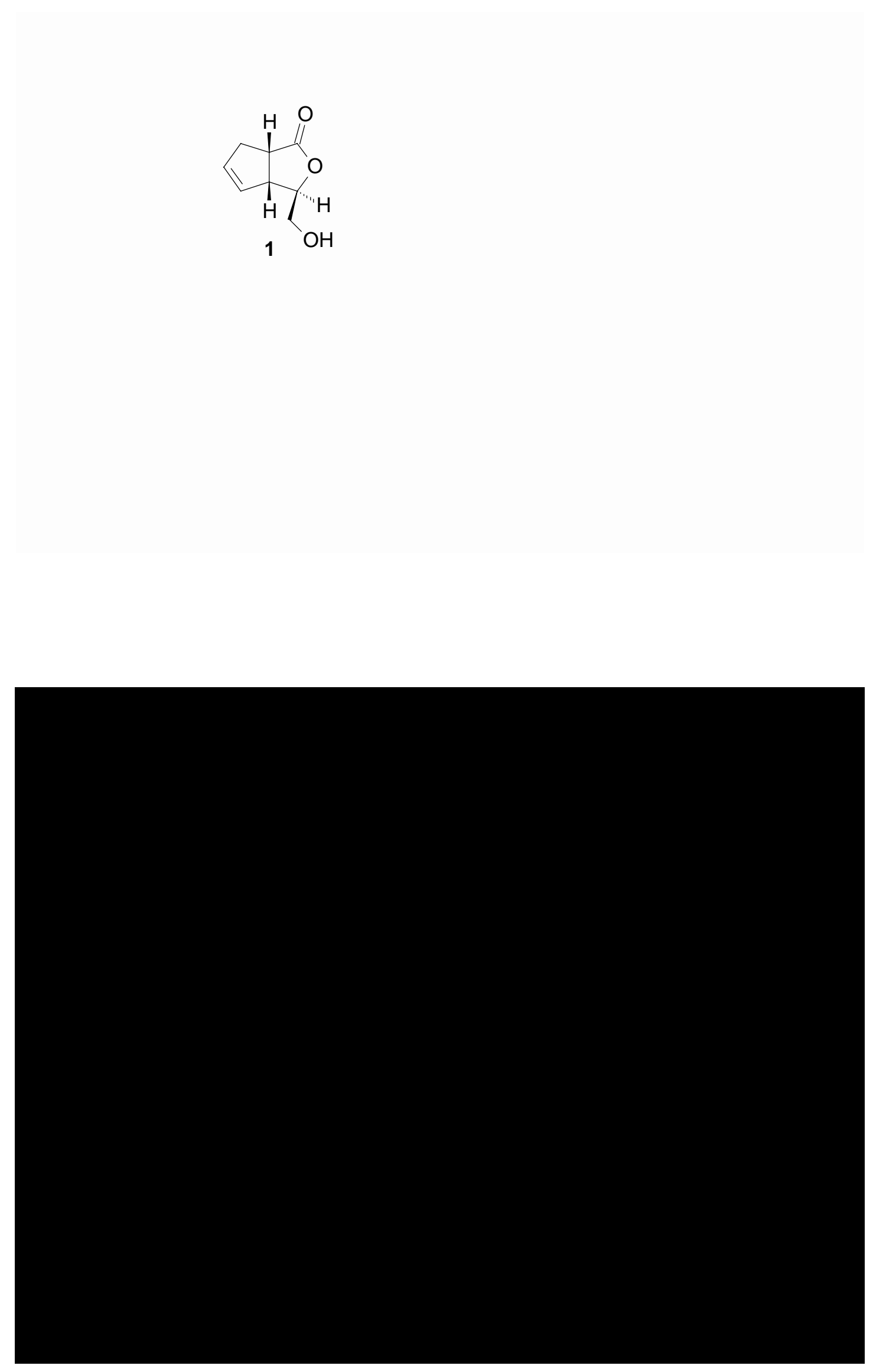

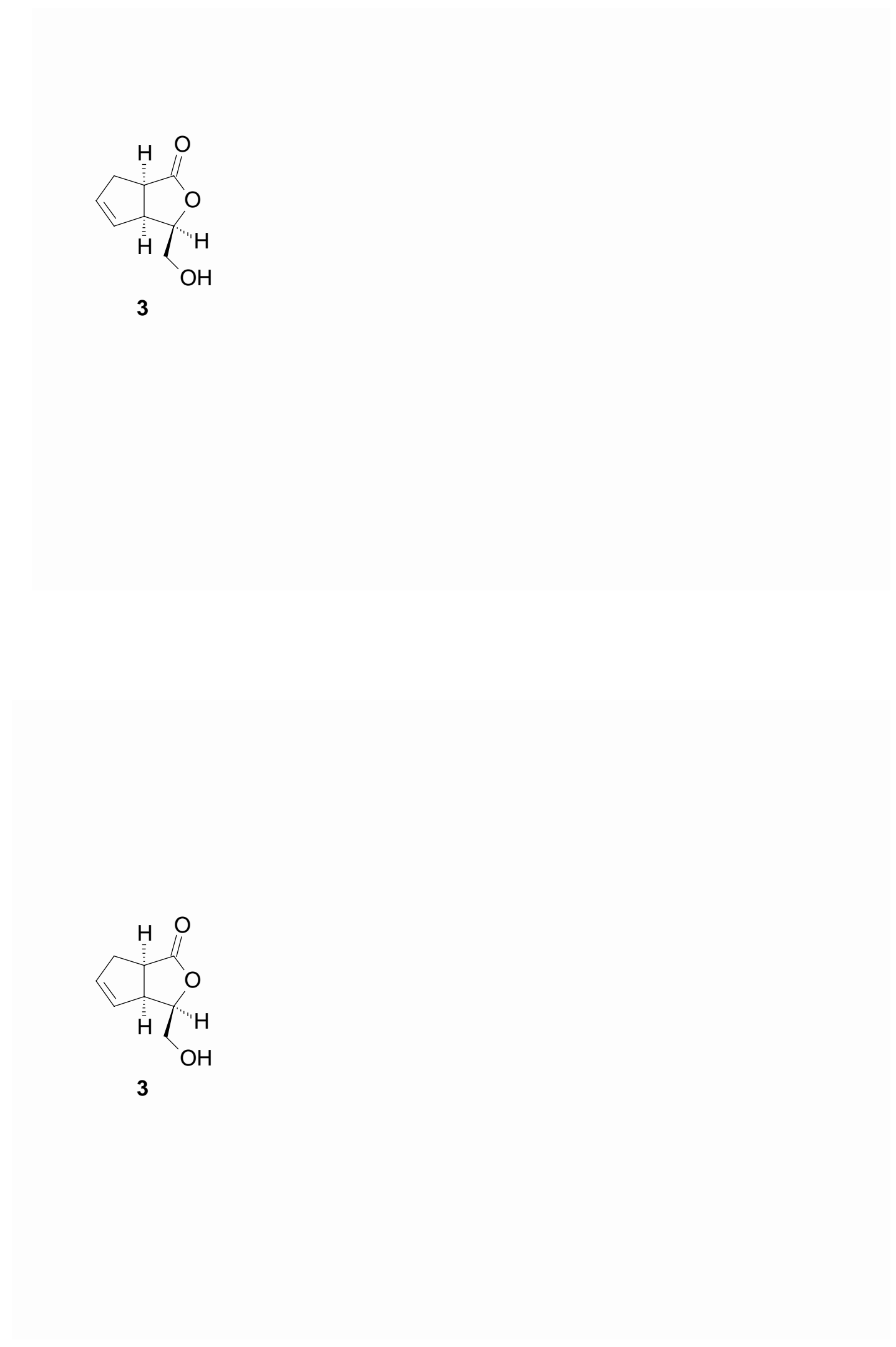


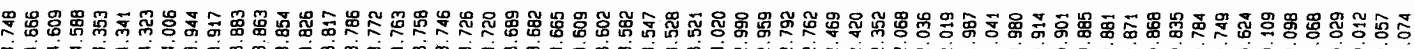

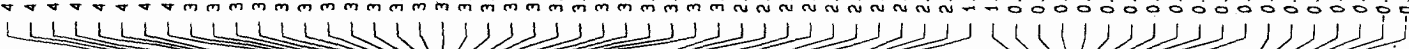

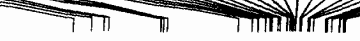
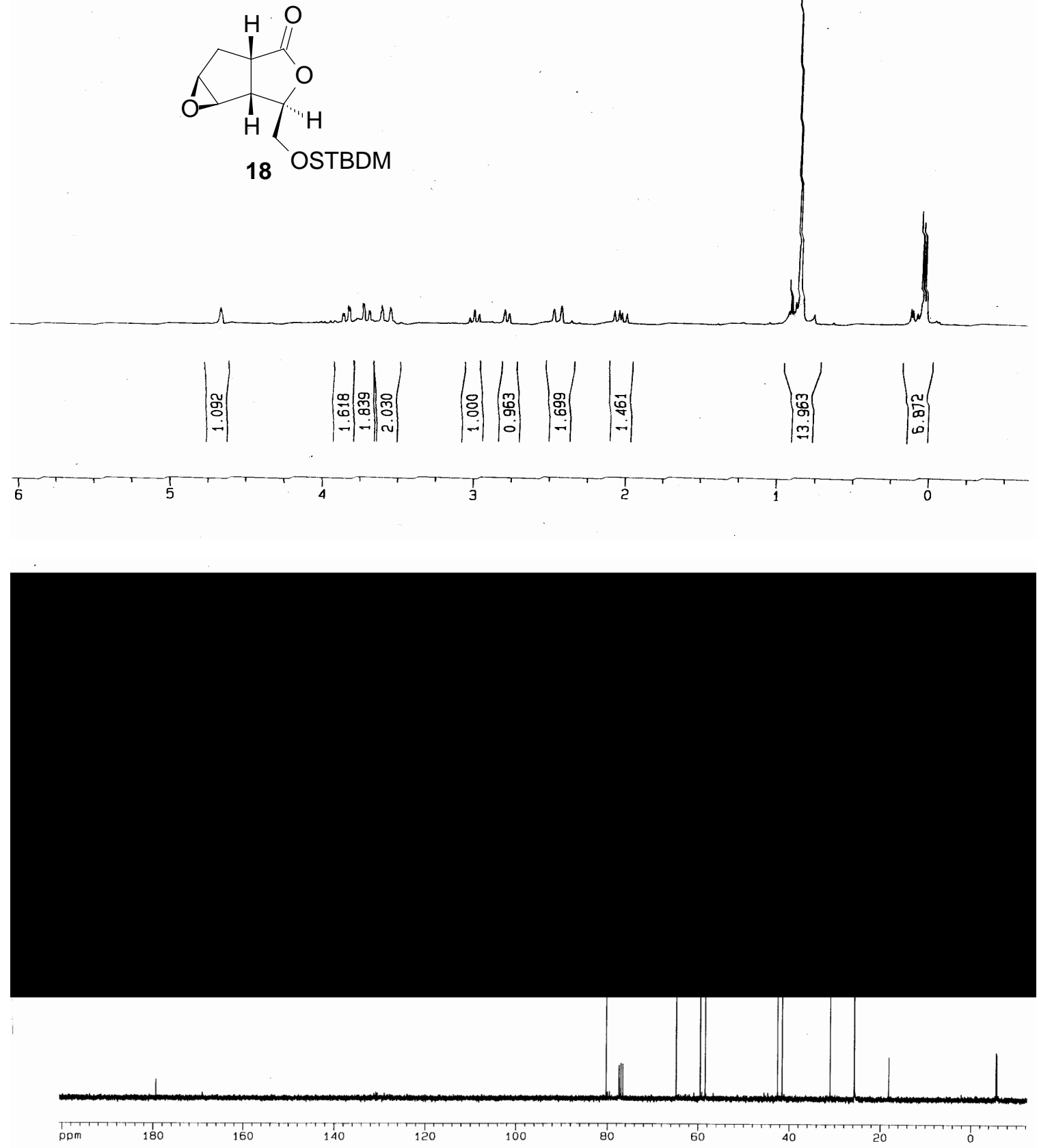

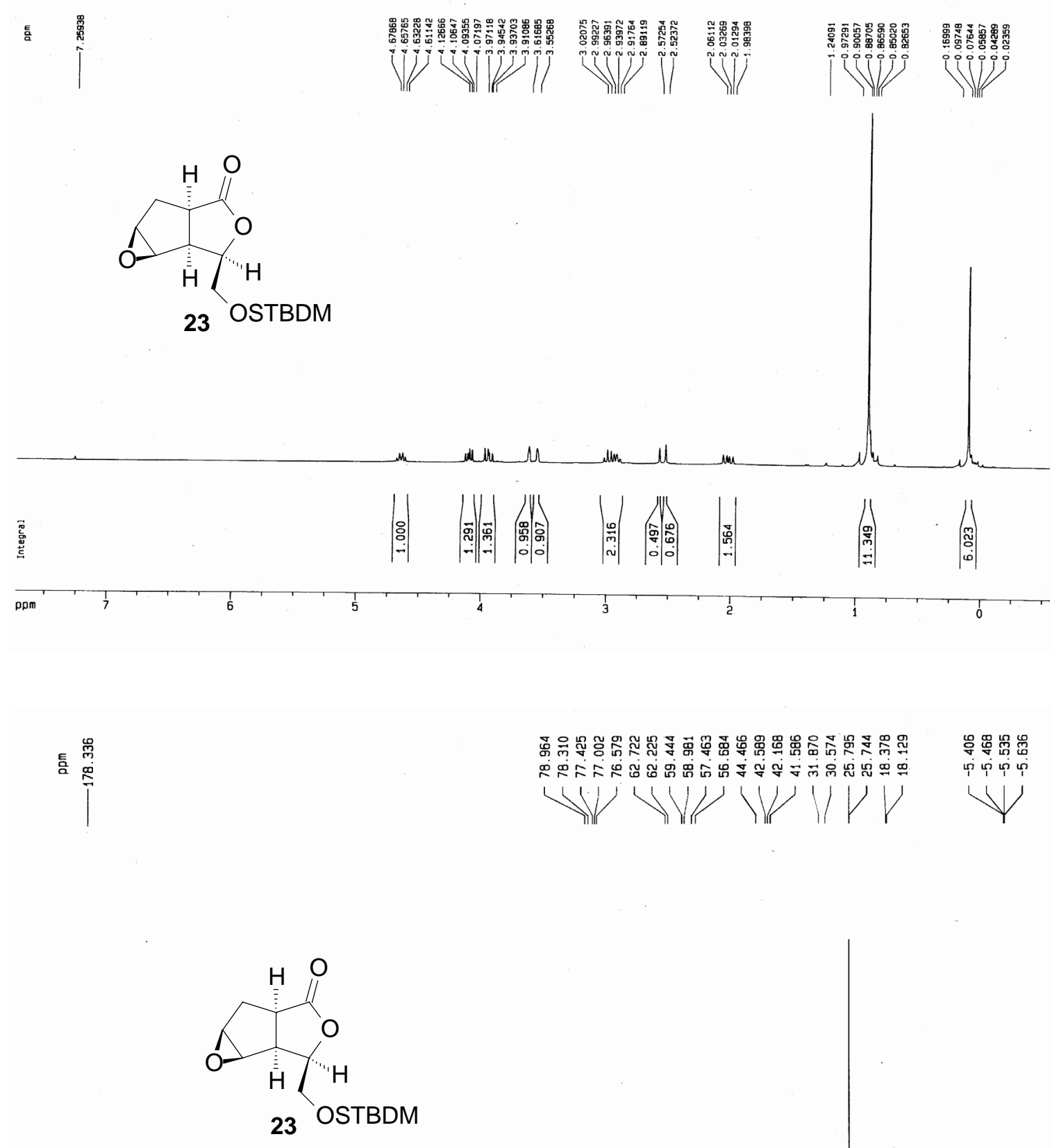

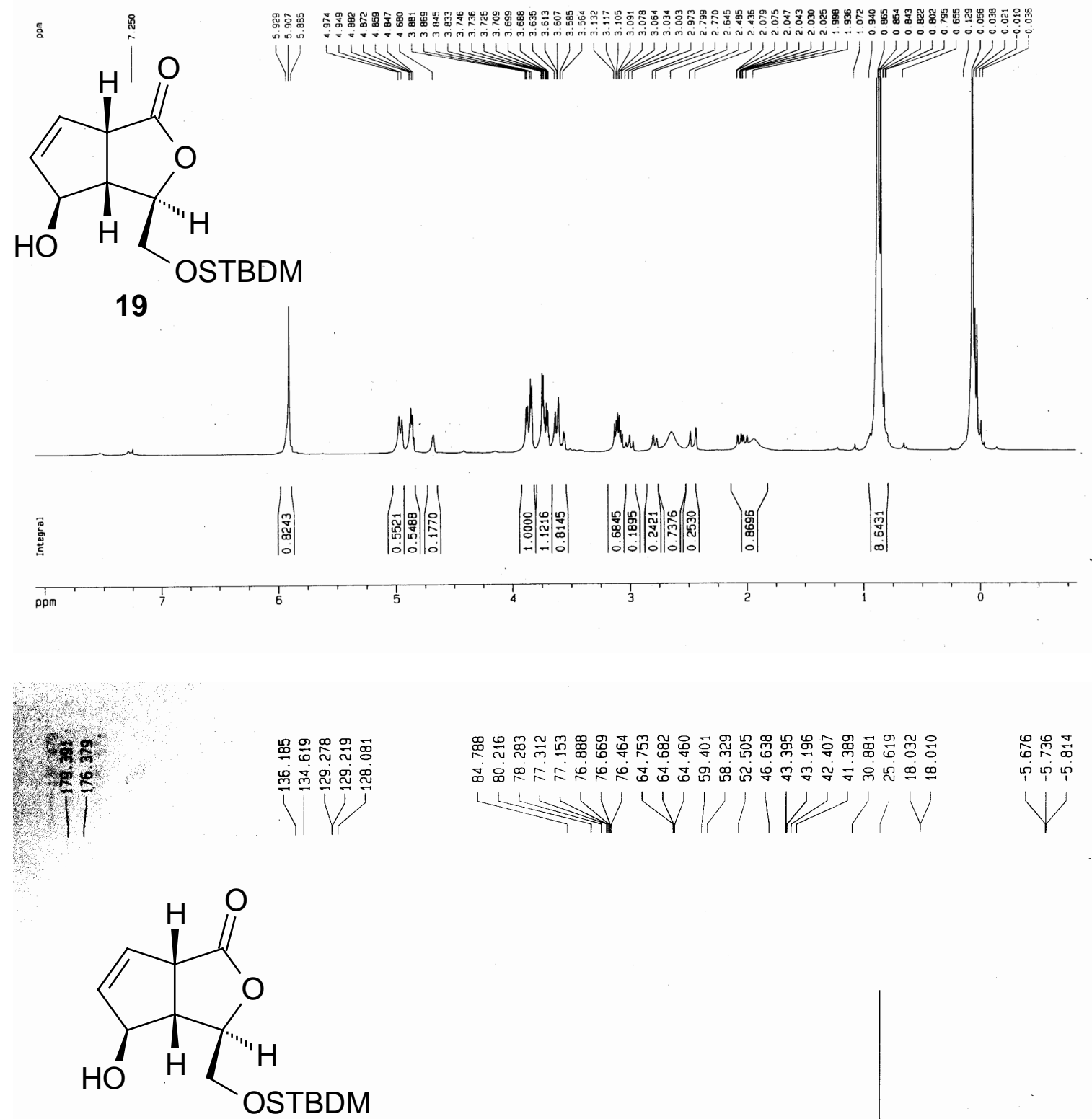

19

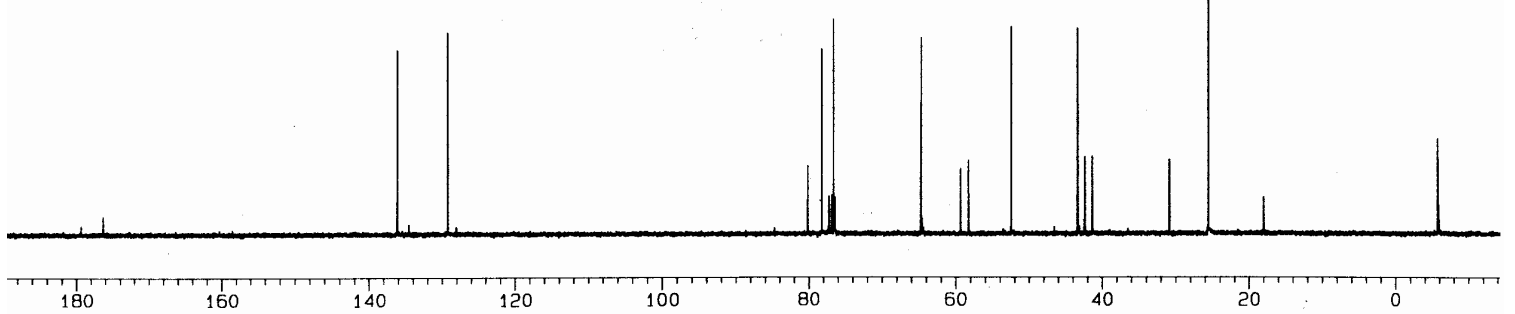


<smiles>[R16][Se-]OC[C@H]1OC(=O)[C@@H]2CC[C@@H](O)[C@@H]12</smiles>

25

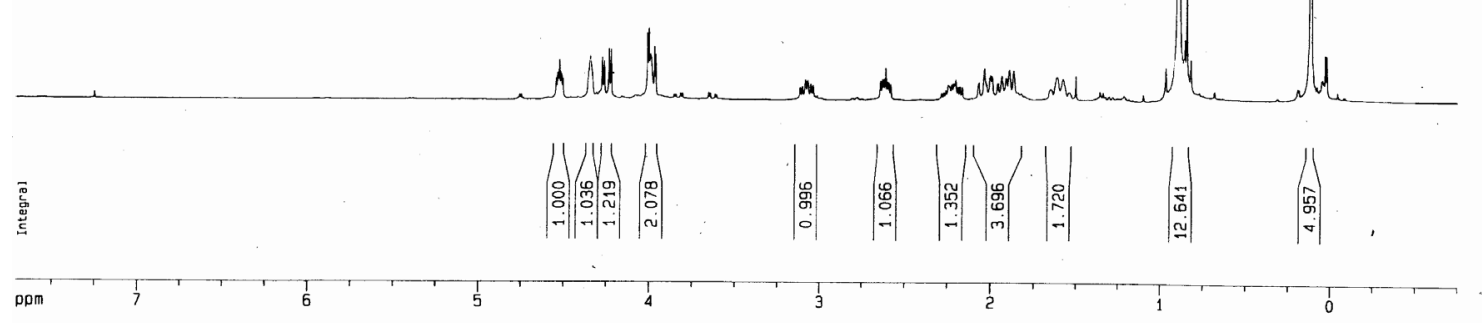

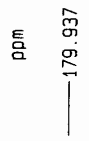

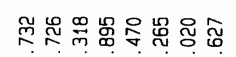

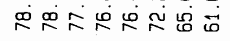

W/1

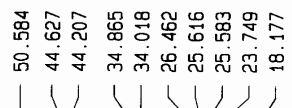

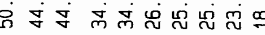

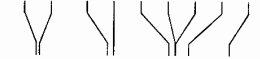

$\stackrel{9}{刃} \cong$

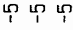

$\psi$<smiles>[R16][SeH]C[C@H]1OC(=O)[C@@H]2CC[C@@H](O)[C@@H]12</smiles>

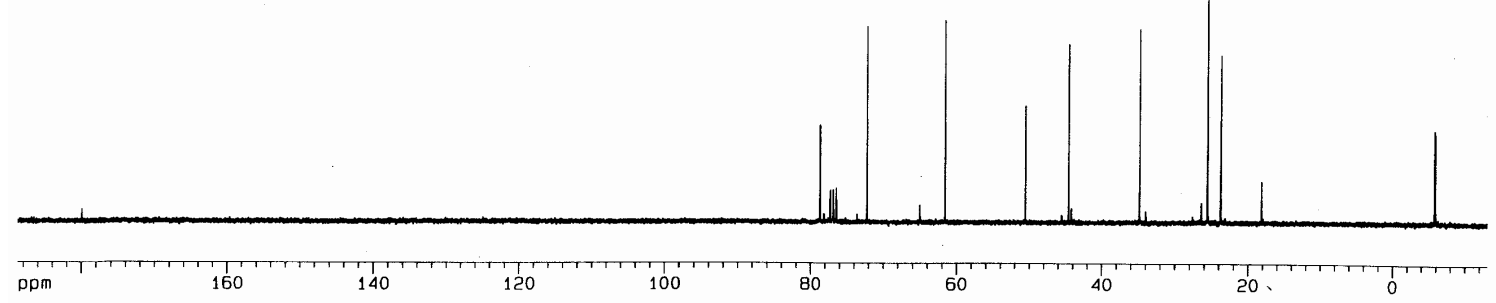



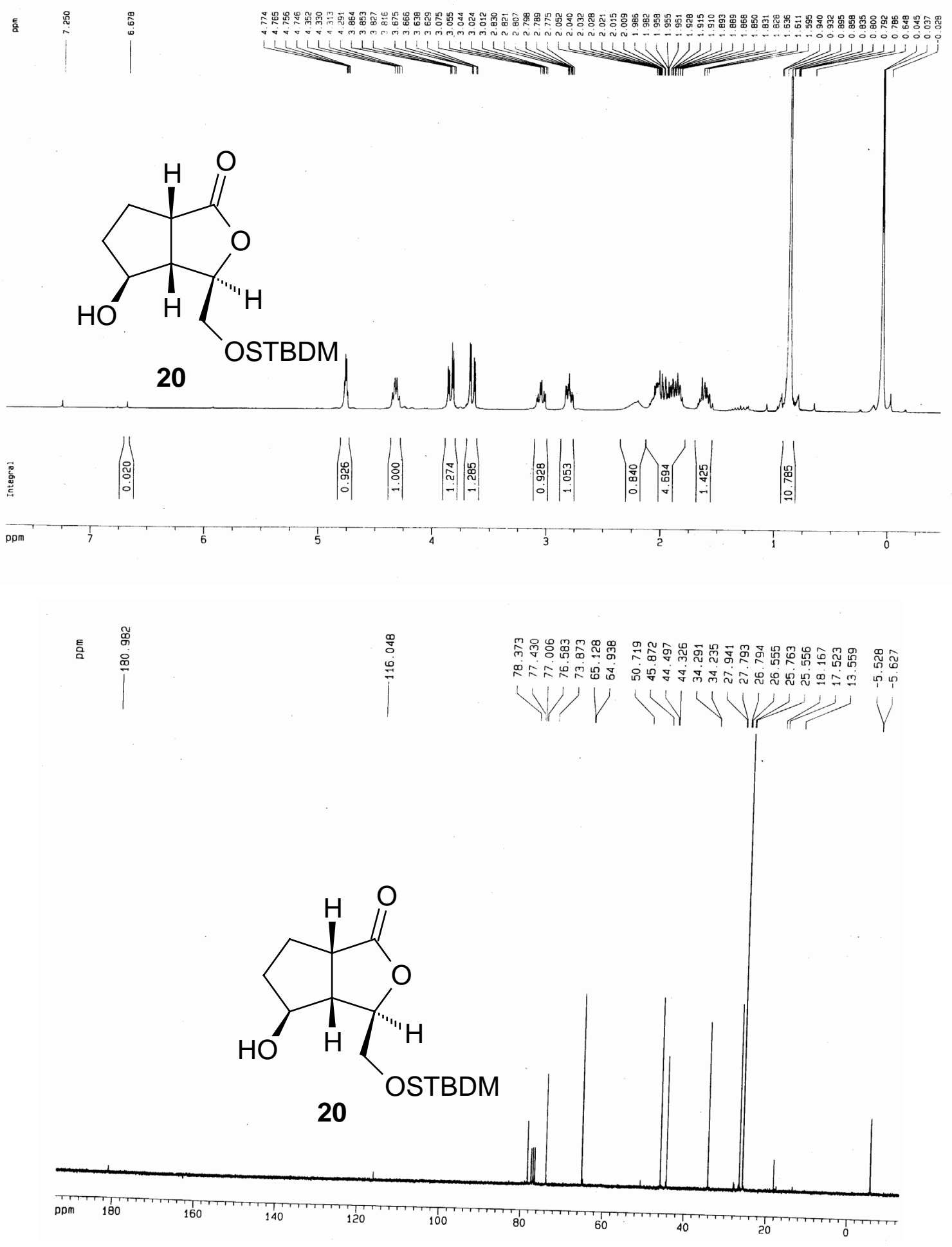


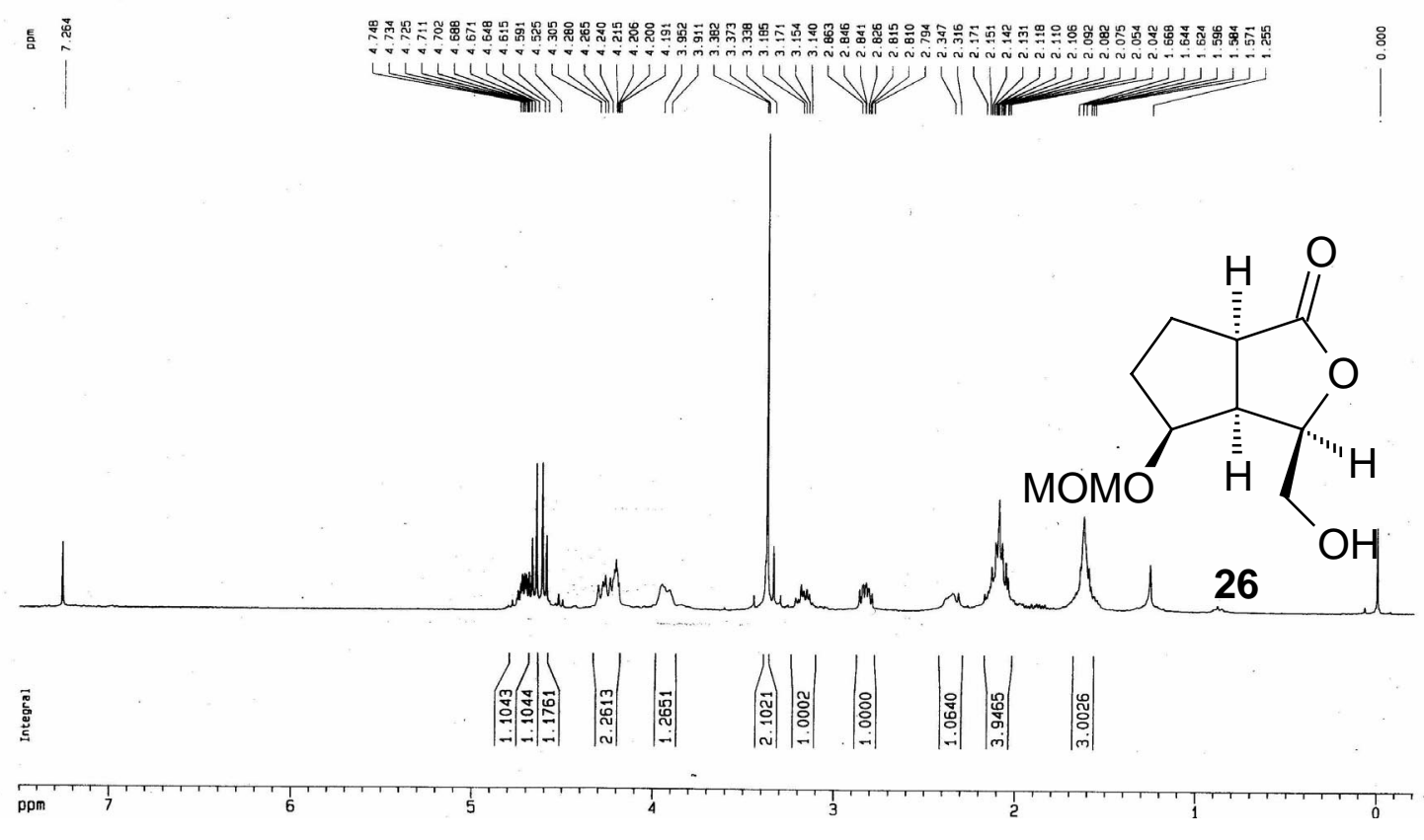

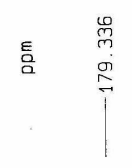

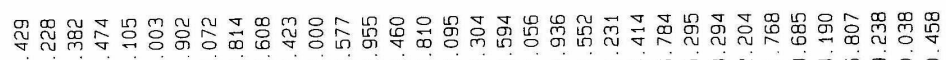

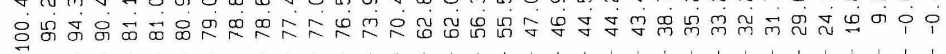

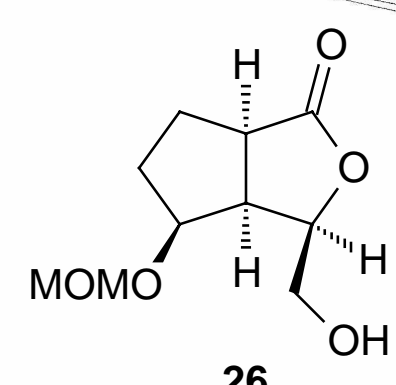

26

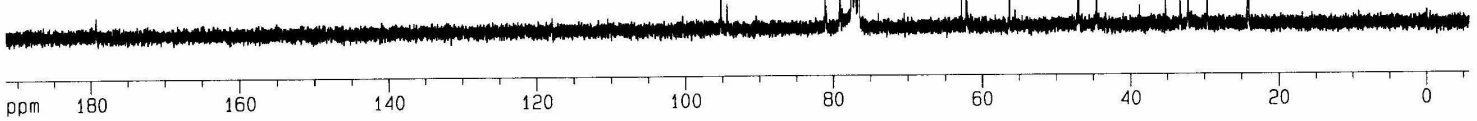

